Logos. Anales del Seminario de Metafísica

ISSN: 1575-6866

https://dx.doi.org/10.5209/asem.76242

\title{
Donde las palabras no alcanzan: violencia y feminicidio
}

Dolores Castrillo Mirat

Las palabras importan. El uso de un significante u otro nunca es inocuo ni a nivel subjetivo ni a nivel político. Es lo que se constata con el significante "feminicidio", neologismo creado por Diana Russell en 1976. Russel define los feminicidios como los crímenes perpetrados contra las mujeres por el simple hecho de serlo. Es la forma más extrema de la violencia contra las mujeres y se considera como el resultado de un proceso constituido por otras formas de maltrato entre las que se cuentan la violación, la privación de libertad, la esclavitud sexual, el maltrato físico, la tortura, la mutilación, la desfiguración... La lista podría alargarse aún más, pero éstas y otras tantas connotaciones incluidas en la palabra "feminicidio" evidencian que lo que está en juego aquí es lo real de un goce sin filtros simbólicos.

Por otro lado hay que destacar que dentro del término feminicidio se incluyen al menos dos modalidades, que es importante distinguir: el feminicidio " intimo" o sea el asesinato de mujeres cometido por hombres con las que las víctimas tenían una relación sentimental, que es el más frecuente, y otra clase de feminicidio que es el asesinato de mujeres anónimas con las cuales los hombres no tenían ninguna relación íntima o sentimental; éste a su vez tiene otra vertiente, la más odiosa y brutal de todas, si es que pueden establecerse grados, que es el feminicidio sistémico como el tristemente célebre de las mujeres asesinadas en Ciudad Juárez.

Tenemos que agradecer al feminismo la invención de este nuevo significante pues en virtud de él los crímenes, las violencias y los abusos contra las mujeres, que han existido desde siempre allí donde ha habido cultura (no hay feminicidio en el mundo animal), pero que permanecían cubiertos por un manto de silencio que buscaba "invisibilizarlos", han pasado a colocarse en el primer plano del debate político. El uso de este significante ha permitido no solo visibilizar los crímenes y la violencia contra las mujeres, sino que ha generado un sinfín de cambios a nivel político, legislativo, jurídico, así como educativo, que buscan poner coto a esta violencia. No obstante, pese a esta proliferación de normas educativas y legislativas, pese a las reivindicaciones de "ni una más", se constata que la violencia no cesa de escribirse sobre los cuerpos de muchas mujeres que una tras otra, día tras día, son maltratadas, violadas, quemadas, acuchilladas...

Frente al real de esta violencia que insiste, el psicoanálisis se ve convocado a participar en el debate sobre el feminicidio, desde una posición que no responde a la lógica de los partidos políticos, pero que tampoco se confunde con la del feminismo, sino que, reconociendo los innegables logros de este movimiento, en sus distintas versiones, se atreve a problematizar algunos de sus planteamientos. 
No discuto el valor de la palabra "feminicidio", que cumple su función en el debate público, pero otra cosa es pensarla como concepto. Creo que habría razones para avalarla también desde el discurso psicoanalítico, pero es necesario ahondar en lo que implica tanto a nivel conceptual como en lo referente a sus posibles causas sin conformarse con explicaciones que, a poco que se profundice, se revelan demasiado simples. La explicación canónica dada por el feminismo es bien conocida: el feminicidio y, en general, la violencia contra las mujeres no es sino la consecuencia del sistema de poder y de dominio masculinos sobre las mujeres instituido por la cultura patriarcal.

No hace falta ser psicoanalista para constatar la evidencia de que, en el mundo de las democracias occidentales, las relaciones entre los hombres y las mujeres no sólo a nivel político y cultural, sino en todos los ámbitos, incluido el amoroso y el sexual, han experimentado tales mutaciones que hacen imposible seguir sosteniendo el mito del macho dominador propio de la era patriarcal. En realidad, este mito empezó a resquebrajarse hace ya mucho tiempo. Como nos recuerda J.A. Miller en su texto Bonjour Sagesse, el filósofo Kojève sostenía, hace ya más de medio siglo, que el tiempo nuevo, que hoy ya no es tan nuevo, se caracterizaba por "la desaparición de lo viril". Lacan retoma la tesis del filósofo en el Seminario 4, en su comentario sobre el pequeño Hans, y explica que, aunque el comportamiento de Hans respondía a la norma heterosexual, pues se interesaba en las chicas, no lo hacía desde lo que a sus ojos era una posición propiamente viril, sino que ocupaba en relación con ellas una posición pasiva. Pero Lacan no considera la posición del pequeño Hans como algo raro o excepcional, sino que hace de ella el paradigma de un nuevo tipo de relaciones entre los sexos que se instala a partir de la generación de 1945. Son ese nuevo tipo de hombres "que esperan que las iniciativas vengan del otro lado, esperan -por decirlo todo-, apunta con crudeza Lacan, que sean ellas las que les quiten los pantalones"1.

En esa misma onda se refiere Lacan a la novela Bonjour tristesse de Françoise Sagan donde en una escena típica de la nouvelle vague, en la playa, la protagonista, ardiente, toma la iniciativa de ir despojando de sus ropas al amante. Este nuevo estilo de las relaciones sexuales que proféticamente supieron ver Kojève y Lacan es hoy ya moneda corriente. Bien ilustrativo al respecto es el último reality televisivo de Metraset que está causando furor. En él se pone en escena a parejas de novios, cada uno por separado, rodeados de pretendientes que van al degüello y donde el reto consiste en si se cae o no en la tentación. Luz Sanchez Mellado en un reciente artículo de El Pais lo comenta así: "Lo nuevo y adictivo, es que las novias joh escándalo ¡han resultado ser más procaces y promiscuas que sus novios. Que ellas son el sexo fuerte y ellos el débil. Que ellos lloran y ellas ríen. Que ellas son las malas y ellos los buenos o los tontos. (...) El clímax fue cuando Estefanía, un mujerón de 34 años, se rio del llanto de su pareja, Christofer, un chaval de 27, mientras ambos veían el video de ella fornicando con otro. Quizá por inédita la escena de una mujer ejerciendo absoluto dominio emocional sobre un hombre resultaba a la vez penosa e hipnótica". ${ }^{2}$

Los cambios en la civilización contemporánea, en la política, en la cultura, en la sociedad, acontecidos en el marco del discurso de la ciencia y del capitalismo, han ido produciendo- es un hecho- una transmutación en la subjetividad, incluido el

Lacan, J.: Seminario 4 La relación de objeto. Buenos Aires-Barcelona, Paidós, 1994, p. 418.

Sánchez Mellado, L.: “¡Estefaníaaa!, El País, 6 de Febrero de 2020. 
campo del fantasma, aunque, por supuesto, estos cambios discursivos tienen efectos diferentes según la singularidad de cada ser hablante. Ya Freud advirtió que nada es más confuso que definir qué sea lo masculino y lo femenino. Por eso señalaba que en el psiquismo la polaridad masculino-femenino quedaba sustituida por la de activopasivo. Es decir, el fantasma, que miente sobre la imposibilidad de la relación sexual, nos da una versión mentirosa de la misma en la que la posición, digamos "clásica", del hombre sería la posición "activa" y la de la mujer, con todos los matices que puedan darse a esta "pasividad", sería la de ocupar el lugar de objeto causa del deseo para el hombre, prestándose a la perversión polimorfa del macho. Esto la puede conducir en ocasiones al estrago, cuando con tal de obtener el signo de amor del hombre es capaz, como nos dice Lacan, de hacer concesiones sin límite "de su cuerpo, de su alma, de sus bienes". Y ésta - y no la de un supuesto masoquismo femenino- que no es sino un fantasma masculino- es una de las razones, sin duda, de por qué a las mujeres les costaba y les sigue costando tanto salir de una relación de maltrato.

Parecería ocioso subrayar que prestarse a ocupar la posición de objeto causa del deseo del hombre no siempre conduce al estrago. Pero hay que recordar que para cierto sector del feminismo el coito, o cualquiera otra forma de relación heterosexual, es un acto que conlleva ya - per se- una violencia intrínseca al sistema de dominación "hetero-patriarcal". Frente a ello, cabría contestar que esto sólo ocurre si del lado de la mujer hay esas "concesiones sin límite" y si del lado del hombre, su perversión polimorfa no está limitada por la castración. La novela de la feminista Marcela Iacub La belle et la bête, escrita en defensa de D.S. K, ha suscitado indignación entre muchas feministas; ella sabía que iba a ser acusada de ir contra la causa de las mujeres, pero aun así se atrevió a afirmar que D.S.K era "un cerdo" pero no un violador; y para mayor escándalo añadía que de ese "cerdo" ella, antes "una monja", se enamoró: "Quería crear- escribe- una teoría del amor a partir de mi situación: una monja que se enamora de un cerdo." ${ }^{3}$ Así, pues, y sin pronunciarme sobre la verdad jurídica del caso D.S.K, hay que reconocer que el testimonio de esta escritora muestra de forma, quizás para algunas un tanto perturbadora, que ocupar la posición de objeto y prestarse a la perversión polimorfa del macho no necesariamente causa estragos en una mujer, $;$ Incluso la puede enamorar;

No obstante, sin que estas posiciones fantasmáticas, digamos "clásicas", de lo masculino y lo femenino hayan desaparecido del todo, la lógica del discurso actual, organizado por los ideales de la igualdad, hace que muchas veces estas posiciones se muevan, se trastoquen o se inviertan, pasando la mujer a ocupar el lugar activo, de sujeto, y el hombre, el pasivo, de objeto. Como apunta M. Fernández Blanco:" Si la mujer no es objeto, es sujeto y el encuentro entre los sexos père-versamente orientado se torna problemático. La mujer-sujeto suscita en muchos hombres, la inhibición, la infantilización o el odio". ${ }^{4}$ Pero a esto habría que agregar que el hombre pasivo, infantilizado, suscita también del lado de no pocas mujeres el desprecio y el odio. Ese hombre desvirilazado, que según Lacan es el paradigma contemporáneo, "obliga" a las mujeres, muchas veces, a ocupar un papel que dicen aborrecer, ese de ser ellas las que "tienen que tirar del carro "en la relación. Se consolida entonces un

3 Iacub, M.: La belle et la bête. Paris, Editions Stock, 2013 Versión digital Kindel, cap. 5, posición 507. (Traducción mía).

$4 \quad$ Fernández Blanco, M.: "Violencia sexual y feminicidio", Letras Lacanianas, no 8, 2014, p.66. 
estilo de relación, que Freud ya constató incluso como prototípico, pero que es cada vez más frecuente en la civilización contemporánea, que es la de la mujer-madre que "tira del carro" y el hombre-niño que se deja llevar por ella en muchos ámbitos de la vida, incluido el sexual. Es muy fácil, inevitable, que este amor de madre hacia el hombre-hijo vire al odio. Sobre todo si se tiene en cuenta que Lacan lejos de identificar a la mujer con la madre establece una oposición de estructura entre ambas. "Con Lacan se puede plantear la cuestión de qué es una verdadera mujer (...), y su respuesta más sencilla es que el carácter verdadero de la femineidad sólo se mide por su distancia con la madre. Tanto menos madre, más mujer. ${ }^{\text {" }}$ Esto no significa obviamente que una madre no pueda ser mujer. La metáfora paterna que es la forma en que Lacan traduce en términos estructurales el Edipo Freudiano supone que ella no sea toda madre, toda para su hijo, que siga siendo mujer. Es decir que el lugar del deseo como mujer debe mantenerse vivo fuera de la relación con el hijo .Puede ocurrir que el hecho de ser madre aplaste la femineidad en una mujer. "Pero -como apunta Miller-solo por cuenta y riesgo propios un hombre olvida que la madre sigue siendo siempre mujer. Si no sabe hacer que la madre de sus hijos se sienta mujer, puede temer que ella encuentre en otro lugar, en el Otro hombre, la relación con el falo que necesita. Hay que decir que algunos de estos hombres llegan a transformar a su esposa en madre sin darle hijos, es decir proponiéndose a sí mismos en ese lugar" ". Esta posición del hombre -hijo, que permite entender como el amor de una mujer hacia el hombre puede virar al odio, es cada vez más frecuente en la época contemporánea y es sin duda uno de los factores de la violencia contra las mujeres en el mundo actual. En no pocas mujeres la desvirilización del hombre suele traducirse en la queja "ya no quedan hombres" la cual las más de las veces se acompaña con el imperativo superyoico: "No eres lo bastante hombre.j Sélo más $i$ “. Se impone así un Che vuoi absolutamente enigmático y feroz no sólo para los hombres, sino también para las mujeres las cuales, como supo advertir Freud, constituyen para sí mismas su propio enigma." Del lado masculino, el efecto de retorno es la demanda desesperada por parte de algunos hombres de que la mujer les confiese el secreto de su goce. Esto aboca, más allá del malentendido, a la violencia. (...) Son hombres que interrogan violentamente a la mujer para que les revele el ser de goce que esconden en su vientre. Para que les confiesen su goce enigmático".7 Lacan se pregunta: “¿Hasta dónde puede soportar el objeto la pregunta? Quizás hasta el momento en que se revele la última falta en ser, hasta el punto en que la pregunta se confunde con la destrucción misma del objeto". "A la destrucción del objeto sigue con frecuencia el suicidio del hombre que, eliminado, el objeto, ya no puede sostenerse un minuto más en la existencia" porque "funda este fantasma sobre la base de su propia eliminación"10

La posición de hombre-niño es la de una dependencia absoluta del Otro, hay un rechazo radical a que una mujer sea no-toda "comprensible" o no-toda de él, y es por eso por lo que la pérdida le resulta insoportable.

\footnotetext{
Miller, J: Introducción a la clínica lacaniana, Barcelona, ELP-RBA Libros, 2006, p. 288

Miller, J: Donc: lógica de la cura, Buenos Aires, Paidós, 2011, pp. 271-272

Ibid., p. 67.

Lacan, J.: Seminario 8 La transferencia, Buenos Aires-Barcelona, Paidós, 2003, p.433.

Fernández Blanco, M.: op. cit., p.67.

10 Lacan, J.: op. cit., p.237.
} 
La declinación de lo viril en el mundo contemporáneo es concomitante de la caída del padre. Por cierto, que patriarcado y padre no son la misma cosa. El patriarcado es una estructura social de poder; el padre, en cambio, una función psíquica, que puede ser ejercida por cualquiera, por una mujer, incluso por un síntoma. Pero es verdad que el discurso de la ciencia y del capitalismo, junto con el patriarcado, se llevaron por delante no sólo al padre como figura de autoridad sino buena parte de su función. Y el declive de lo viril, propio de la época contemporánea, como precisa J.A. Miller, no es pensable sin el declive del padre. Él lo explica a partir de las fórmulas de la sexuación. "Qué es la desaparición de lo viril? Es lo que resta de la fórmula de la sexuación masculina si se la oblitera la parte izquierda de la fórmula. Solo queda entonces simplemente el todos, el todos juntos, el todos iguales, de la democracia (...) Detrás de la desaparición de lo viril hay el declive del padre que Lacan señala desde Los complejos familiares ${ }^{11}$.

Formular de esta manera el declive del padre, donde al obliterar la parte izquierda de la fórmula, la de la excepción, sólo queda el lado del para todos, permite sostener, a mi juicio, que el mundo, hoy, es un mundo con menos padre, pero no menos falocéntrico. Lejos de que haya una "feminización del mundo" me inclinaría a decir que lo que hoy impera es una" falizicación del mundo" entendiendo aquí "falicización" (podría haber otras maneras de entenderlo) como una intensificación del para todos, es decir, un rechazo de la imposibilidad de nombrar el goce Otro, un rechazo del no todo-femenino, lo que conlleva una impotencia para soportar la relación con el Otro sexo. Como afirma Jorge Alemán, "la violencia contra las mujeres constituye un hecho criminal sistémico que confirma la tesis de Lacan de que una impotencia con lo real tiende a resolverse con una llamada a la fuerza". En este aspecto el machismo habría que entenderlo "no tanto como una fuerza expansiva de una potencia desatada y encarnada por los digamos hombres -machos, sino como una respuesta a un proceso de perdida de la virilidad, acentuado hoy día por los dispositivos homogeneizadores del liberalismo subsumidos en el para todos". ${ }^{12}$

Así pues, frente a la idea feminista que ve en el machismo y el patriarcado la causa de la violencia contra las mujeres se puede sostener que ésta "está más relacionada con la impotencia que siempre se resuelve con un acto de fuerza. Siendo el propio capitalismo el que se llevó por delante el propio Nombre del Padre". ${ }^{13}$

Es cierto que en los últimos tiempos la crítica del feminismo al orden patriarcal podría tener motivos para sostenerse pues hay razones para echarse a temblar ante lo que está sucediendo. Si el empuje de las mujeres por hacerse un lugar en la cultura ha podido culminar en lo que algunos han denominado una "feminización del mundo" (término respecto al cual ya he expresado mis reservas), en las últimas décadas una gran parte de éste está atestiguando una ola de "masculinización". Vuelve con fuerza, valga la redundancia, la imagen de hombres fuertes encarnada en lideres ultra machistas como Putin, Trump y Bolsonaro, o como nuestro sonrojante “ caballero hispánico" Santiago Abascal, que si no se atreven a incitar descaradamente a ejercer la violencia contra las mujeres, sí exhiben de forma desvergonzada la degradación de las mujeres a mero objeto de goce sexual o algo peor.: "Yo a usted no

\footnotetext{
Miller, J.A.: "Bonjour sagesse", La cause du désir, nº 95, 2017, p.84. (La traducción es mía).

12 Alemán, J.: Capitalismo: crimen perfecto, Barcelona, Ned Ediciones, 2018. Versión digital Kindel, cap. IV, I, posición 1865.

$13 \quad$ Ibid. Posición 1882.
} 
la violaría porque no se lo merece” le espetó con espantosa obscenidad Bolsonaro a una diputada. Estos líderes ultra-machistas encarnan sin duda el retorno, mitad feroz, mitad esperpéntico, de ese Padre cuyo declive, iniciado ya en tiempos del propio Freud, no ha hecho sino profundizar su caída para convertirse en el signo paradigmático de los tiempos hiper modernos. Y ese retorno a su vez es emblemático de las ansiedades y angustias que en muchos hombres y también en no pocas mujeres ha provocado la caída de los antiguos códigos con los que se creía que era posible ordenar las relaciones entre los sexos y evitar el malentendido estructural entre ellos. Estos líderes erigidos en Padres salvadores quieren evitar el malentendido entre los sexos reconduciendo a la sexualidad a lo que según ellos y la Santa Madre Iglesia siempre fue y debe seguir siendo: la unión natural de un hombre y una mujer para traer hijos a este mundo. Ellos se han dado la misión de imponer a todos esa sexualidad "norme mâle"14 de toda la vida y limpiar al mundo de esos goces sucios de gays, lesbianas, trans y demás escorias que objetan el para todos y constituyen una ofensa imperdonable a La ley natural y a La ley de Dios.

Pero esto no significa que podamos seguir sosteniendo la idea de que el patriarcado es la causa, hoy en día, de la violencia contra las mujeres. Esa creencia en el patriarcado es un modo de seguir sosteniendo la consistencia de un Padre que, aunque retorne hoy de forma caricaturescamente feroz, hace ya mucho tiempo que se evaporó para siempre. De hecho, no pocos de los hombres que ejercen la violencia contra las mujeres, lejos de encarnar el macho dominador, según testimonios de las propias mujeres, son tipos frágiles, hechos polvo, devorados por el goce de la droga o el alcohol, de una u otra forma "hombres-desastre", como se refiere una analizante a sus sucesivos partenaires por parte de alguno de los cuales fue objeto de maltrato, hombres cuya violencia es más bien el resultado de una impotencia que siempre se resuelve con un acto de fuerza.

Sin embargo, si no podemos atribuir la violencia actual contra las mujeres al régimen patriarcal, tampoco podemos decir que ésta pueda explicarse de modo exhaustivo por la caída del padre. Por la sencilla razón de que violencia contra las mujeres ha habido desde siempre, tanto en las culturales patriarcales como en la época de la caída del padre. Si ésta permite explicar algunas de las formas del malestar actual entre los sexos que pueden conducir al feminicidio, esta caída no es empero la causa estructural del mismo. De ello se desprende que el verdadero problema no es el padre sino el goce. Hoy se ha revelado que el padre no era sino un semblante que nunca pudo apaciguar el malentendido incurable entre los goces, ni siquiera en las épocas donde su poder se asentaba en el patriarcado.

Por esta razón Lacan nos dice que existen, ya desde los tiempos de Aquiles, y con independencia del sexo biológico, dos modos de gozar que nunca se encontrarán: el de Aquiles todo fálico y el de la tortuga no-toda fálica. Mientras que el primero se centra en el tener, en la apropiación del objeto, en el control, en lo que se puede no sólo localizar, sino nombrar, e incluso medir y cuantificar, el de una mujer se muestra sin medida, infinito, irreductible, no sólo a un órgano, sino a la palabra misma. Algunas, también algunos, pueden experimentar puntualmente este extraño goce, pero nunca podrán decir en qué consiste ese goce femenino que, no por casualidad, Lacan llama Otro y que encarna una alteridad radical, un real que las palabras no alcanzan a nombrar.

14 Lacan juega con el equívoco significante al que se presta la lengua francesa entre normale y norme mâle, normal y norma macho. 
Frente a la angustia suscitada por ese goce Otro, imposible de simbolizar, nómada, excéntrico, no todo sometido al régimen fálico, se puede disparar la violencia masculina como un intento ferozmente patológico de colonizar un espacio que carece de confines. Cómo señala M. Bassols, el pasaje al acto violento" viene en el lugar de una palabra imposible de decir"15. En esta misma línea cabe afirmar, que el feminicidio, donde se consuma el silencio acéfalo y brutal de la pulsión, supone una extinción de la dimensión de la palabra. Siempre y cuando convengamos que la dimensión de la palabra comporta no sólo lo que se puede decir, sino también lo que no se puede decir. A este respecto, las violaciones en manada, o los asesinatos de mujeres indiscriminadas por grupos de hombres, como sucedió en Juárez, muestran que en lugar de la dimensión simbólica funciona una especie de ley imaginaria de la horda; una fraternidad de goce, en la que la fusión entre sus miembros se basa en el odio a un enemigo común: el chivo expiatorio de las mujeres, que permite ubicar paranoicamente, el propio odio indecible hacia sí mismos, en un afuera vivido como lugar de amenaza permanente.

La dimensión de la palabra implica hacer la experiencia de la alteridad y del límite inherente a la palabra misma. Cuando ese límite no se acepta, se produce el pasaje al acto violento que es un rechazo feroz de la relación con el límite, con el trauma de la inexistencia de la relación sexual y del malentendido incurable entre los goces. En el feminicidio- y por eso esta palabra es la que debe usarse para estos asesinatos- lo que el hombre busca eliminar en una mujer es ese goce radicalmente Otro, extraño, que se le impone, en su opacidad indecible, de una forma absolutamente insoportable.

Ese odio al goce del Otro es al mismo tiempo el odio al propio goce, a lo que el sujeto no puede poner en palabras sobre sí mismo. Esto no sólo ocurre en los hombres, también en una mujer hay un odio, un rechazo a ese goce Otro que, si bien con menos frecuencia que en los hombres, la puede llevar al pasaje al acto violento, como un modo de golpear en el otro, o en su propio cuerpo, eso que de sí misma no puede articular con palabras.

Frente al recurso al acto violento que cortocircuita la palabra y que hoy, pese a todas las legislaciones, las normas y los protocolos educativos, no cesa en su insistencia, diría, parafraseando a J.A Miller, que el psicoanálisis es una invitación a hacer "un esfuerzo de poesía". Si por poesía entendemos el esfuerzo de poner en palabras ese goce que perturba a cada ser hablante, no para decirlo todo lo cual es imposible, sino para, alcanzado ese límite, encontrar una manera de hacer con ese resto irreductible otra cosa distinta de la destrucción del otro y /o de la autodestrucción. En situaciones de violencia, de desconcierto o de errancia, siempre es aconsejable recordar el verso del poeta: "Si he perdido la vida, el tiempo, todo lo que tiré, como un anillo al agua, si he perdido la voz en la maleza, me queda la palabra"16

\section{Referencias bibliográficas}

Alemán, J.: Capitalismo: crimen perfecto, Barcelona, Ned Ediciones, 2018. Versión digital Kindel.

Bassols, M.: Lo femenino, entre centro y ausencia, Buenos Aires, Gramma, 2017.

Bassols, M.: Lo femenino, entre centro y ausencia, Buenos Aires, Gramma, 2017, p.146.

16 De Otero, B.: En el principio en Obra completa (1935-1977), Madrid, Círculo de Lectores, 2013, p.97. 
Fernández Blanco, M.: "Violencia sexual y feminicidio", Letras Lacanianas, no 8, 2014.

Iacub, M.: La belle et la bête. Paris, Editions Stock, 2013 Versión digital Kindel.

Lacan, J.: Seminario 4 La relación de objeto. Buenos Aires-Barcelona, Paidós, 1994.

Lacan, J.: Seminario 8 La transferencia, Buenos Aires-Barcelona, Paidós, 2003.

Miller, J.A.: "Bonjour sagesse", La cause du désir, no 95, 2017.

Otero de, B.: En el principio en Obra completa (1935-1977), Madrid, Círculo de Lectores, 2013.

Sánchez Mellado, L.: “¡Estefaníaaa!, El País, 6 de Febrero de 2021. 